\title{
Leaf:fruit Ratio Affects the Proteomic Profile of Grape Berry Skins
}

\author{
Ben-Hong $\mathrm{Wu}^{1}$, Ning Niu ${ }^{1,2}$, Ji-Hu Li, and Shao-Hua $\mathrm{Li}^{2,3,4}$, \\ Beijing Key Laboratory of Grape Science and Enology, and CAS Key Laboratory of Plant \\ Resources, Institute of Botany, the Chinese Academy of Sciences, Beijing 100093, P.R. China
}

\begin{abstract}
AdDITIONAL INDEX wORDS. anthocyanin, berry composition, crop load, two-dimensional gel electrophoresis, Vitis vinifera
Abstract. The most obvious effects of a low leaf:fruit (LF) ratio [two leaves for one cluster per shoot (LF2)] on grape (Vitis vinifera) berries are suppressed anthocyanin biosynthesis in the berry skin, decreased berry weight and soluble solids concentration, and increased titratable acidity. In this study, proteins isolated from berry skins grown under low and high LF ratio conditions, LF2 and LF12, respectively, were characterized by two-dimensional gel electrophoresis coupled to mass spectrometry. A survey of $\approx 600$ to 700 spots from berry skin yielded 77 proteins with differential expression between LF12 and LF2 treatments. Of these, the 59 proteins that were identified consisted of 47 proteins that were down-regulated and 12 that were up-regulated under LF2 conditions compared with LF12 conditions. Most proteins involved in metabolism, energy, transcription, protein synthesis, binding function, signal transduction, and cell defense were down-regulated in LF2 berries, whereas two important enzymes of anthocyanin biosynthesis, chalcone synthase and dihydroflavonol reductase, were not detected. Only a few proteins (e.g., two heat shock proteins related to protein fate and nutrient reservoir storage protein) were found to be up-regulated in LF2 berries. This suggested that, with the exception of secondary metabolism, many proteomic events may have an effect on anthocyanin synthesis in the skins responding to LF.
\end{abstract}

Source-sink relationships (mainly leaves vs. reproductive organs) play an important role in fruit growth and quality with respect to fruit size, color, and chemical composition. Grape is a species well suited for exploring the mechanisms that govern these links, partly as a result of its great architectural and physiological plasticity. Reducing the number of nodes per vine through increased pruning severity, the cluster number per vine through cluster thinning, and/or the number of leaves through leaf removal can alter the source-sink relationships and result in different cropload levels.

Berry growth and chemical composition can be largely regulated by cropload levels (Hunter and Visser, 1988; Kliewer and Dokoozlian, 2005). Low cropload, which is achieved by increasing the leaf:fruit ratio, generally leads to a larger fruit size in grapes (Petrie et al., 2000) as well as mango [Mangifera indica (Chacko et al., 1982; Léchaudel et al., 2005)] and peach [Prunus persica (Souty et al., 1999)]. Concentrations of soluble solids in grape berries (Bravdo et al., 1985; Edson et al., 1995; Etchebarne et al., 2010; Howell et al., 1987) and of anthocyanins in berry skins (Kliewer and Weaver, 1971) have repeatedly been found to be decreased by high cropload. To date there have been controversial results regarding titratable acidity with different experimenters finding increases (Reynolds, 1989; Wolpert et al., 1983), decreases (Bravdo et al., 1985),

Received for publication 16 July 2013. Accepted for publication 18 Sept. 2013. The research was supported by CAS Youth Innovation Promotion Association, National Natural Science Foundation of China (NSFC 31071757; 31372047) and National 948 Project from the Ministry of Agriculture.

We thank Prof. Douglas D. Archbold, University of Kentucky, for critical review of the manuscript.

${ }^{1}$ Ben-Hong Wu and Ning Niu contributed equally to this work.

${ }^{2}$ Present address: Shijiazhuang Academy of Agriculture and Forestry Sciences, Shijiazhuang 050041, P.R. China.

${ }^{3}$ Present address: Key Laboratory of Plant Germplasm Enhancement and Speciality Agriculture, Wuhan Botanical Garden, the Chinese Academy of Sciences, Wuhan 430074, P.R. China.

${ }^{4}$ Corresponding author. E-mail: shhli@wbgcas.cn. or no change at a high cropload (Yamane and Shibayama, 2006). A combination treatment of cluster thinning/leaf removal and girdling is considered effective for improving fruit quality and skin coloration of grapes in warm regions (Weaver, 1963). However, apart from these insights, previous studies have more often dealt with the effect of different cropload levels on berry growth and juice composition characteristics; there is as yet little information available on metabolic changes that occur.

Proteomic analysis allows the large-scale study of proteins to gain insight into overall metabolic activities. Variation in the proteomic profile of grape berries has been evaluated during berry development and in response to environmental factors such as water stress (Deytieux et al., 2007; Grimplet et al., 2009; Martínez-Esteso et al., 2011). We have recently published our findings that in addition to proteins involved in secondary metabolism [e.g., UDP-glucose flavonoid 3-O-glucosyltransferase (UFGT)], proteins involved in photosynthesis and heat shock proteins were less accumulated in the skin of berries subjected to sunlight exclusion, whereas proteins related to glycolysis, the tricarboxylic-acid cycle, protein synthesis, and biogenesis of cellular components were generally up-regulated (Niu et al., 2013). These findings highlighted the need to improve our current understanding of the proteomic events that surround the arrestment of color development in grape berry skin in response to sunlight exclusion. The findings of our previous study also demonstrated the suitability and advantages of large-scale proteomic analysis techniques for identifying metabolic changes. To date, no proteomic analysis has been performed with grape berries responding to different cropload levels. Berry skin was of particular interest in this study because berry skin color and anthocyanin biosynthesis may be subject to change by LF. Presumably proteins other than those involved in the well-known anthocyanin synthesis pathway may be regulated by this ratio. The aim of the present study was to assess the effect of different LF treatments on protein 
variation in grape berry skin using two-dimensional gel electrophoresis (2-DE).

\section{Materials and Methods}

Plant materials and treatments. Five-year-old vines of the red table grape 'Jingyan', grafted on 'Beta' rootstocks, were used in this study. The vines were planted in 2005 in the experimental vineyard of the Institute of Botany, Chinese Academy of Sciences, Beijing (lat. 39 $90^{\prime} \mathrm{N}$, long. 116 $30^{\prime} \mathrm{E}$ ), and trained to a trellis system with north-south-oriented rows, spaced $1.5 \mathrm{~m}$ apart within the row and $2.5 \mathrm{~m}$ apart between rows. They were maintained under routine cultivation, including irrigation, fertilization, soil management, pruning, and disease control.

Vines were selected on 8 June $2010, \approx 14 \mathrm{~d}$ after anthesis ( 14 DAA). Fifteen to 20 shoots were chosen from a total of 12 vines with homogeneous vegetative and reproductive appearance, and the clusters were thinned to leave one cluster with a varying number of leaves per shoot. The effects of LF18 (18 leaves per shoot) and LF10 on berry weight, soluble sugars, and organic acid content have previously been found to not be significant (Etchebarne et al., 2010). In the same study, LF10 increased berry weight and soluble sugars under irrigation conditions compared with LF5; however, the treatments still had little effect on organic acid contents. To strengthen the effects of LF treatments, LF12 and LF2 were applied on five to eight shoots from each vine in this study (Fig. 1). Retained leaves in each treatment consisted of fully expanded leaves prepared by topping and/or removal of small basal leaves. Number of berries was thinned to 60 to 70 berries per cluster. Cuts of width $\approx 10 \mathrm{~mm}$ were made on the shoot-bearing cordon with a girdling knife to isolate the experimental shoots and control the transport of assimilates between the treated and non-experimental parts of the vines through the phloem but allowing water flow through the xylem (Fig. 1). The girdle was renewed whenever it healed.

SAMPLING AND BERRY COMPOSITION. Three replicates of two clusters from each of the two treatments were sampled every 5 to $8 \mathrm{~d}$ from 24 DAA (18 June). The final harvest date was 66 DAA (30 July), when berries in the LF12 treatment had reached maturity. Berries in the LF2 treatment were less developed (less ripe) at the final harvest date. Berry maturity was based on seed color turning dark brown without senescence of berry tissue and

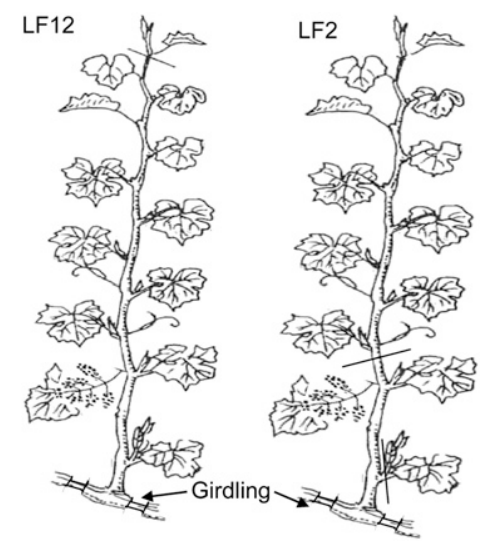

Fig. 1. Diagram of leaf:fruit ratio (LF) treatments. LF12 and LF2, respectively, refer to 12 and two fully expanded grape leaves (prepared by topping and/or removing small basal leaves) retained for one cluster per shoot. Girdles of $\approx 10 \mathrm{~mm}$ width were made on the shoot-bearing cordon. on previous records and experience. All berries from the two clusters of each replicate were sampled at each sampling date, weighed, and measured for longitudinal and transverse diameter. Berry skin was peeled, frozen in liquid nitrogen, and stored at $-80^{\circ} \mathrm{C}$. Anthocyanin concentration in berry skin was determined by high-performance liquid chromatography using a P680 system (Dionex, Sunnyvale, CA) following Liang et al. (2008), expressed as milligrams of cyanidin 3-monoglucoside chloride that was purchased from PhytoLab (Vestenbergsgreuth, Germany). After removing skins, the berry pulp was crushed to obtain juice using a hand juice crusher. Soluble solids concentration (SSC) was measured with a digital handheld refractometer (Atago, Tokyo, Japan) and titratable acidity (TA) as grams per liter of tartaric acid was assayed by titration up to $\mathrm{pH} 8.2$ with $0.1 \mathrm{~N} \mathrm{NaOH}$.

Protein extraction. The berry skin proteomic profiles were compared between LF12 and LF2 treatments at 43 DAA. This date was chosen because at this time point, total anthocyanins exhibited a sharp increase for LF12 but did not increase for LF2. The frozen berry skin ( $4 \mathrm{~g}$ ) was ground to a fine powder in liquid nitrogen using a pre-cooled pestle and mortar. The frozen power was transferred to a clean centrifuge tube and suspended in $12 \mathrm{~mL}$ of cold extraction buffer $(0.1 \mathrm{M}$ TRIS-HCl, $\mathrm{pH} 7.5,5 \mathrm{~mm}$ ethylenediaminetetraacetic acid, $10 \mathrm{~mm}$ phenylmethanesulfonyl fluoride, $2 \% \beta$-mercaptoethanol, $0.1 \mathrm{M} \mathrm{KCl}, 0.7 \mathrm{M}$ sucrose, $1 \%$ polyvinylpolypyrrolidone) (Deytieux et al., 2007). The suspension was vortexed for $30 \mathrm{~s}$ and incubated at $4{ }^{\circ} \mathrm{C}$ for $1 \mathrm{~h}$ after which an equal volume of phenol-TRIS-HCl at $\mathrm{pH} 7.5$ was added. The suspension was vortexed for $30 \mathrm{~s}$ and incubated at $-20^{\circ} \mathrm{C}$ for $1 \mathrm{~h}$. The homogenate was centrifuged for $30 \mathrm{~min}$ at $10,000 \mathrm{~g}_{\mathrm{n}}$ at $4{ }^{\circ} \mathrm{C}$ and the phenol phase was collected. The aqueous phase was washed again in $4 \mathrm{~mL}$ of extraction buffer and $4 \mathrm{~mL}$ of phenol-TRIS- $\mathrm{HCl}$ at $\mathrm{pH}$ 7.5 , vortexed for $30 \mathrm{~s}$, incubated for $30 \mathrm{~min}$ at $-20{ }^{\circ} \mathrm{C}$, and centrifuged for $30 \mathrm{~min}$ at $10,000 \mathrm{~g}_{\mathrm{n}}$ at $4{ }^{\circ} \mathrm{C}$. The supernatants were combined. Extracted proteins were precipitated by adding five volumes of ice-cold $0.1 \mathrm{M}$ ammonium acetate in methanol to the phenol phase. The resulting suspension was vortexed for $30 \mathrm{~s}$ and incubated at $-20{ }^{\circ} \mathrm{C}$ overnight. The next day, the precipitated proteins were recovered by centrifugation $(30 \mathrm{~min}$, $35,000 g_{\mathrm{n}}, 4{ }^{\circ} \mathrm{C}$ ) and the pellets were successively washed with ice-cold $0.1 \mathrm{M}$ ammonium acetate in methanol, methanol, acetone, and finally $80 \%$ acetone. The final pellet was vacuumdried and re-suspended in $800 \mu \mathrm{L}$ isoelectrofocusing (IEF) solubilization buffer [7 $\mathrm{M}$ urea, $2 \mathrm{M}$ thiourea, $40 \mathrm{~mm}$ dithiothreitol (DTT), 2\% (w/v) 3-[(3-Cholamidopropyl)-dimethylammonio]1-propane sulfonate (CHAPS), $2 \%(\mathrm{v} / \mathrm{v})$ immobilized $\mathrm{pH}$ gradients (IPG) buffer, $1 \%(\mathrm{w} / \mathrm{v})$ Triton X-100]. The suspension was vortexed for $30 \mathrm{~s}$ and incubated for $4 \mathrm{~h}$ at room temperature and then centrifuged at $40,000 g_{n}$ at $4{ }^{\circ} \mathrm{C}$ for $20 \mathrm{~min}$ to remove the insoluble material. The supernatant was transferred to a new tube.

Two independent protein extractions for each of three biological replicates were performed and combined. Protein concentration was measured by a Bio-Rad protein assay (BioRad, Hercules, CA) using bovine serum albumin as a standard.

Two-dimensional IEF/SDS-PAGE. Proteins $(1200 \mu \mathrm{g})$ dissolved in IEF solubilization buffer were loaded on immobiline linear gradient $\mathrm{pH} 4-7$ dry strips (length $24 \mathrm{~cm}$ ) by $16 \mathrm{~h}$ passive rehydration at $20^{\circ} \mathrm{C}$ with a current limit of $50 \mu \mathrm{A}$ per strip. An IPG phor II electrophoresis system (GE Healthcare, Little Chalfont, U.K.) was used with a program of $2 \mathrm{~h}$ at $150 \mathrm{~V}$, $1 \mathrm{~h}$ at $500 \mathrm{~V}, 100 \mathrm{~V} \cdot \mathrm{h}^{-1}$ to $1000 \mathrm{~V}, 2000 \mathrm{~V} \cdot \mathrm{h}^{-1}$ to $8000 \mathrm{~V}$, and 
finally $5 \mathrm{~h}$ at $8000 \mathrm{~V}$. The strips were equilibrated in two steps with an equilibration buffer containing $0.05 \mathrm{M}$ Tris- $\mathrm{HCl}(\mathrm{pH}$ 8.8), $6 \mathrm{M}$ urea, $30 \%(\mathrm{v} / \mathrm{v})$ glycerol, $2 \%(\mathrm{w} / \mathrm{v})$ sodium dodecyl sulfate (SDS), and $0.125 \%(\mathrm{w} / \mathrm{v})$ DTT for $15 \mathrm{~min}$ in the first step and with the same buffer containing $125 \mathrm{~mm}$ iodoacetamide and no DTT for another $15 \mathrm{~min}$ in the second.

Two-dimension SDS-polyacrylamide gel electrophoresis was performed using an ETTAN DALTsix system (GE Healthcare). Equilibrated strips were placed on top of $12.5 \%$ acrylamide resolving gels. Molecular weight markers (prestained protein marker, broad range; New England Biolabs, Hertfordshire, U.K.), covering a 10 - to $100-\mathrm{kDa}$ range, were loaded on the acidic side of each gel. An agarose sealing solution (0.5\% agarose in running buffer) was loaded onto the gel strips. Electrophoresis was performed at $15^{\circ} \mathrm{C}$ in a Laemmli running buffer $(25 \mathrm{~mm}$ Tris-HCl $\mathrm{pH} 8.3,192 \mathrm{~mm}$ glycine, $0.1 \% \mathrm{SDS}$ ) at $50 \mathrm{~V}$ for $1 \mathrm{~h}$ and then at $200 \mathrm{~V}$ for $10 \mathrm{~h}$ until the dye front (bromophenol blue) reached the bottom of the gel.

Staining And ANALYSis of 2-DE Gels. After electrophoresis, gels were stained with colloidal Coomassie brilliant blue (CBB R-250). Stained gels were scanned at 300 dpi using a scanner (UMAX Power Look 2100XL; Maxium Technologies, Taipei, China). Image elaboration and data analysis of the scanned gels were performed using Image Master 2D Platinum software (Version 5.01; GE Healthcare), which allows spot detection, quantization, background subtraction, and spot matching among multiple gels. Automatic matching by software was complemented by manual matching. Protein abundance of each spot was expressed as relative volume (percent volume) normalized against total spot volume. Only spots with relative volume greater than $0.1 \%$ in at least two gels of three biological replicates were subjected to the comparison between LF12 and LF2 treatments. Spots were considered to be differentially expressed between LF12 and LF2 treatments if differences in spot relative volume between the two treatments were significant at the level of 0.05 (Student's $t$ test) and displayed at least a 2-fold change.

IN-GEL DIGESTION AND MALDI-TOF MS ANALYSIS. Protein spots were excised from the CBB-stained 2-DE gels and transferred to a sterilized Eppendorf tube. Gel fragments were washed three times with deionized water obtained from a water purification system (Milli-Q Element; Millipore, Bedford, MA) and then destained with solution containing $50 \mathrm{~mm} \mathrm{NH}_{4} \mathrm{HCO}_{3}$ and $50 \% \mathrm{v} / \mathrm{v}$ acetonitrile (ACN) for $20 \mathrm{~min}$ at $37^{\circ} \mathrm{C}$. The destaining step was repeated until the gel fragments were colorless. Gel fragments were subsequently dehydrated and dried using $100 \%$ ACN. They were rehydrated with $0.01 \mu \mathrm{g} \cdot \mu \mathrm{L}^{-1}$ sequencing grade modified trypsin in $25 \mathrm{~mm} \mathrm{NH}_{4} \mathrm{HCO}_{3}$ at $4{ }^{\circ} \mathrm{C}$ for $1 \mathrm{~h}$. After an overnight incubation in the same solution at $37^{\circ} \mathrm{C}$, the resulting tryptic fragments were washed three times with $0.1 \%$ trifluoroacetic acid (TFA) in $50 \%$ ACN to collect peptides. The peptide solution was concentrated to $10 \mu \mathrm{L}$ and cocrystallized with one volume of saturated $\alpha$-cyano-4hydroxycinnamic acid in 50\% v/v ACN containing $1 \%$ TFA. Tryptic peptide masses were measured with a matrix-assisted laser desorption ionization-time-of-flight (MALDI-TOF) mass spectrometer (Shimadzu Biotech, Kyoto, Japan).

All the reagents used in this study were obtained from Sigma-Aldrich (St. Louis, MO) and all the materials and instruments used in 2-DE from GE Healthcare.

Protein identification and functional Classes. Proteins were identified by peptide mass fingerprinting (PMF) using
MASCOT software (Matrix Science, London, U.K.) to search the National Center for Biotechnology Information database. Viridiplantae (green plants) was chosen as the taxonomic category. Searches were performed using the following settingsfixed modifications: carbamidomethyl; variable modifications: methionine oxidation; enzyme: trypsin; one miscleavage of trypsin allowed; mass endurance for peptides: $100 \mathrm{ppm}$. Identification confidence criteria were determined as a sequence coverage of any protein of no less than $12 \%$ of matching peptides in addition to a minimum molecular weight search (MOWSE) score of 50. The best matches with high confidence levels had a priority for selection (Yang et al., 2007). Theoretical mass and $\mathrm{p} I$ of identified proteins were calculated from sequence data with the ExPASy Compute pI/Mw tool (Artimo et al., 2012). The identified proteins were assigned to Munich Information Center for Protein Sequences (MIPS) functional categories set up at the Munich Information Center for Protein Sequences (Moser et al., 2005) based on published annotation.

\section{Results and Discussion}

BERRY GROWTH AND COMPOSITION. Berry longitudinal and transverse diameters and berry weight progressively increased during berry development under both LF12 and LF2 treatments, being significantly higher under LF12 treatment from 30 DAA until maturity (Fig. 2). At maturity, berry weight under LF12 treatment was $\approx 1.43$ times greater that under LF2 treatment. A similar negative influence of high cropload on berry weight has been widely reported (Candolfi-Vasconcellos and Koblet, 1990; Dokoozlian and Hirschfelt, 1995; Hummell and David, 1998; Kliewer and Weaver, 1971; Reynolds et al., 1986), although other studies did not find such effects (Edson et al., 1995; Etchebarne et al., 2010; Morris et al., 2004). This variation in findings might be the result of the extent of cropload and irrigation conditions.

An increase in SSC with berry development was observed under both LF12 and LF2 treatments, although SSC under LF2 showed a decrease near maturity. Berries from the LF2 treatment showed significantly less SSC than those from LF12 treatment, except on the first sampling date (24 DAA). In contrast to SSC, differences in TA between LF12 and LF2 were less evident and not significantly different from 24 to 43 DAA. Post-43 DAA TA was significantly higher under LF2. At maturity, SSC under LF12 was 1.66 times greater that of LF2, whereas TA under LF12 was $64 \%$ of that of LF2. The most obvious difference between treatments was observed in skin coloration and total anthocyanin concentration. Skin colored well under LF12 but did not color at all under LF2 (not shown). Total anthocyanin concentration under LF12 was low at 24 and 30 DAA, and from 35 DAA until maturity anthocyanin continuously accumulated and reached $655.99 \mathrm{mg} \cdot \mathrm{kg}^{-1}$ fresh weight $(\mathrm{FW})$. In contrast, total anthocyanin concentration under LF2 remained at a very low level (less than $5.32 \mathrm{mg} \cdot \mathrm{kg}^{-1} \mathrm{FW}$ ) during the sampling period. The results for SSC and anthocyanins were in accordance with previous studies (Weaver, 1963) with both measurements decreasing proportionally with decreasing leaves per cluster. The effect of the treatments on TA was similar to some prior studies that have shown that TA increases with enhanced cropload (Reynolds, 1989; Wolpert et al., 1983). However, other researchers have found a decrease (Bravdo et al., 1985) or no effect on TA with enhanced cropload (Yamane and Shibayama, 2006). 


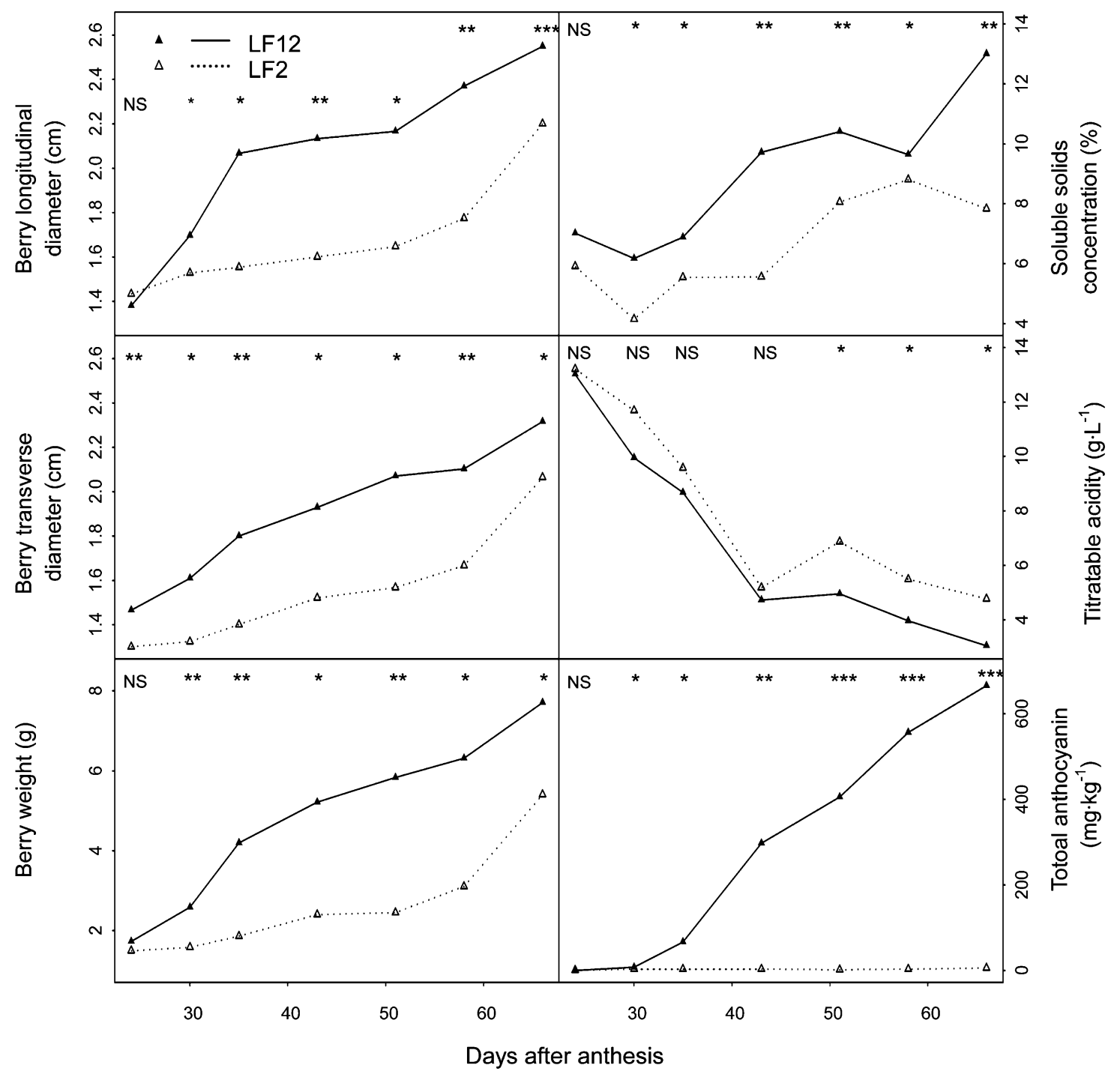

Fig. 2. Berry growth and composition in 'Jingyan' grape berry skin at leaf:fruit ratio 12 (LF12) and leaf:fruit ratio two (LF2) during berry development. Ns indicates nonsignificant difference. *, **, and *** indicate a significant difference at $P<0.05, P<0.01$, and $P<0.001$ (Student's $t$ test between LF12 and LF2 treatments on each date).

Comparative analysis of PRoteomic profiles. Approximately 600 to 700 spots were visible across the three replicate gels of the two treatments (Fig. 3). The expression pattern of 77 proteins differed significantly between the treatments. Compared with LF2, 55 proteins were down-regulated and 22 proteins were up-regulated under the LF12 treatment. Of the 77 differentially regulated proteins subjected to MALDI-TOF analysis, 47 down-regulated and 12 up-regulated proteins under LF2 were successfully identified by PMFs through MALDITOF mass spectrometry and MASCOT database searches (Table 1). Six proteins identified were not homologous to any known protein in the database and were designated "unknown" and "unclassified." The remaining 53 proteins were classified by function into metabolism (16 proteins), energy (20), storage (two), transcription (two), protein synthesis (three), protein fate (three), protein with binding function (one), transport (one), signal transduction (two), and cell rescue (two) categories, according to the annotation in the MIPS database.

Proteins involved in Metabolism. The most obvious effect of LF2 treatment was a lack of anthocyanin accumulation in berry skin. Anthocyanins are generally considered to be secondary metabolites and part of the large family collectively known as flavonoids (Holton and Cornish, 1995). Two identified proteins, chalcone synthase [CHS (spot 37)] and dihydroflavonol reductase [DFR (spot 41)], were classified as connected to secondary metabolism (MIPS function 01.20) and were highly expressed in berry skin under the LF12 treatment but not the LF2 treatment. CHS is the first key enzyme in the phenylpropanoid pathway to channel molecules toward flavonoids and produce the flavonoid chalcone. Alternatively, DFR catalyzes the first step in the conversion of dihydroflavonols to anthocyanins (Boss et al., 1996). The down-regulation of these two enzymes at key branch points likely resulted in the absence of substrate for anthocyanin biosynthesis. However, most enzymes involved in the anthocyanin biosynthetic pathway such as phenylalanine ammonia lyase, chalcone isomerase (CHI), flavanone 3-hydroxylase $(\mathrm{F} 3 \mathrm{H})$, flavonoid $3^{\prime}$-hydroxylase $\left(\mathrm{F} 3^{\prime} \mathrm{H}\right)$, flavonoid $3^{\prime}, 5^{\prime}$ hydroxylase $\left(\mathrm{F}^{\prime} 5^{\prime} \mathrm{H}\right)$, leucoanthocyanidin dioxygenase (LDOX), and especially UFGT were not detected. In grape 

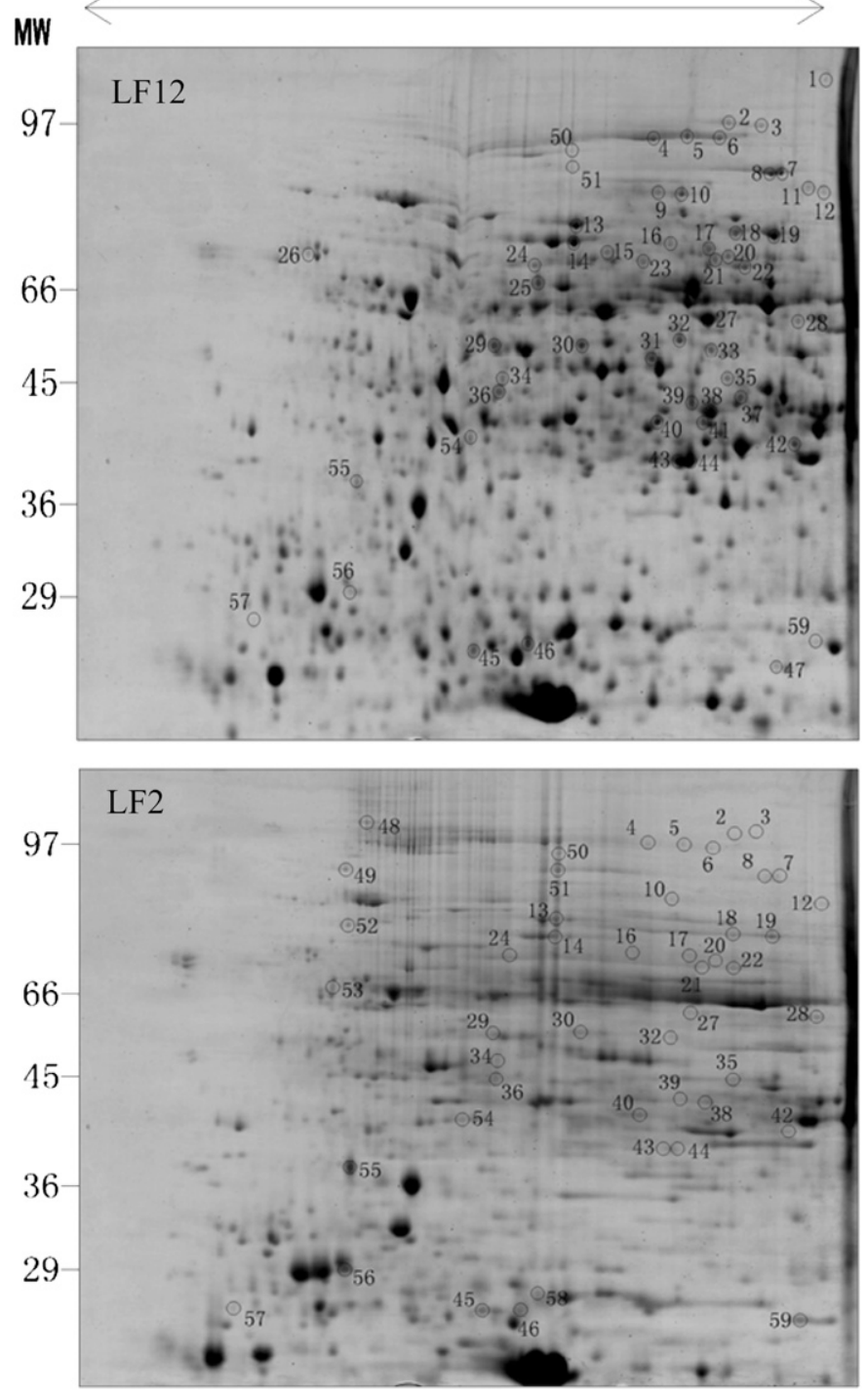

Fig. 3. Two-dimensional gel electrophoresis polyacrylamide gel electrophoresis analysis of the proteins in 'Jingyan' grape berry skin at leaf:fruit ratio 12 (LF12) and leaf:fruit ratio two (LF2) at $43 \mathrm{~d}$ after anthesis. Differentially regulated proteins between LF12 and LF2 treatments are indicated by circles and spot numbers on a representative gel. See Table 1 for a detailed list of proteins.

berry skin, UFGT has been widely considered the key enzyme in determining grape coloration (Boss et al., 1996; Kobayashi et al., 2001). UFGT expression was impaired by a retrotransposoninduced mutation of $V v M Y B a l$ in white skins (Kobayashi et al., $2002,2004)$. At the transcriptional level, the expression of $U F G T$ as well as $F 3 H, F 3^{\prime} H, F 3^{\prime} 5^{\prime} H, L D O X$, and $D F R$ were found to be substantially lower or absent in green-skinned compared with red-skinned berries (Castellarin et al., 2007). At the proteomic level, CHS, CHI, F3H, LDOX, and UFGT were also found to be preferentially accumulated in the colored skin (Deytieux et al., 2007; Grimplet et al., 2009). In this study, with the exception of CHS and DFR, the predicted down-regulation of enzymes involved in this pathway under LF2 treatment was not found. Robinson and Davies (2000) reported that enzymes involved in this pathway were present at low levels, making their assay difficult. In fact, in a proteomic analysis conducted on the skin of the grape 'Barbera' at different stages of ripening, no proteins related to the anthocyanin biosynthesis pathway were detected, although a 10 -fold increase in the anthocyanin content occurred from véraison $\left(\approx 0.3 \mathrm{mg} \cdot \mathrm{g}^{-1} \mathrm{FW}\right)$ to maturity $\left(\approx 3.0 \mathrm{mg} \cdot \mathrm{g}^{-1} \mathrm{FW}\right)$ (Negri et al., 2008b). Giribaldi et al. (2007) reported that when a sudden accumulation of anthocyanin in 'Nebbiolo Lampia' skins took place at veraison, only CHI protein content increased and no other proteins involved in anthocyanin synthesis were observed. It is likely that this effect was caused by the experimental conditions and requires further verification.

Amino acid metabolism (function 01.01) was much less active in berry skin under LF2 treatment. 2-Oxoglutarate dehydrogenase complex (spot 2) irreversibly degrades the metabolite 2-oxoglutarate (Bunik and Fernie, 2009), which affects anthocyanidin synthase by catalyzing the formation of the colored anthocyanidins from the colorless leucoanthocyanidins (Saito et al., 1999). Delta-1-pyrroline-5-carboxylate dehydrogenase (spot 23) is the second key enzyme for proline degradation. Cysteine desulfurylase (spot 33), which catalyzes the formation of L-alanine from the substrate L-cysteine, is involved in the syntheses of many kinds of sulfur-containing biomolecules (Chen et al., 2012). S-adenosylmethionine synthetase [spot 30 (known as methionine adenosyltransferase)] is considered the rate-limiting step of the methionine cycle (Markham and Pajares, 2009) and catalyzes the formation of Sadenosylmethionine, which has been suggested to be essential for gene transcription, cell proliferation, and production of secondary metabolites (Yoon et al., 2012). Although it is well known that phenylalanine is required as a precursor for anthocyanins, there is little information on the effect of the amino acid metabolism on anthocyanin synthesis. Hilbert et al. (2003) found that high nitrogen supply increased total amino acid content in berries of 'Merlot', whereas it decreased total anthocyanin content. Proteins involved in amino acid metabolism were observed to generally accumulate with berry development (Negri et al., 2008b). In this study, the inactivity of the amino acid metabolism under low LF treatment may be partially ascribed to the delayed berry development. This suggests that the availability of amino acids may not be the limiting factor of anthocyanin synthesis, as suggested by Hilbert et al. (2003). In addition, 5-methyltetrahydropteroyltriglutamatehomocysteine methyltransferase [spots 7, 8, and 51 (also known as methionine synthase)], which participates in methionine metabolism by regenerating methionine, was either downregulated (spots 7 and 8) or up-regulated (spot 51) in berry skin under LF2 treatment. This enzyme may be present in low amounts in plants, and understanding of its molecular and biochemical characterization is still limited (Hesse et al., 2004).

Except for nicotinamide adenine dinucleotide (NAD)dependent epimerase/dehydratase (spot 58), all other proteins (spots 16, 25, 42, 45) related to C-compound metabolism (function 01.05) were down-regulated under LF2 treatment. Among them, inorganic pyrophosphatase (spot 45) has been considered the possible prime cause of the intense breakdown of malate during grape berry development because it increased throughout development with acceleration during ripening (Terrier et al., 2001). Deytieux et al. (2007) found that proteins involved in carbohydrate metabolism were expressed less at the end of color change $(100 \%$ red) than at its onset $(10 \%$ red), suggesting that the berry skin is a source of carbohydrates for 


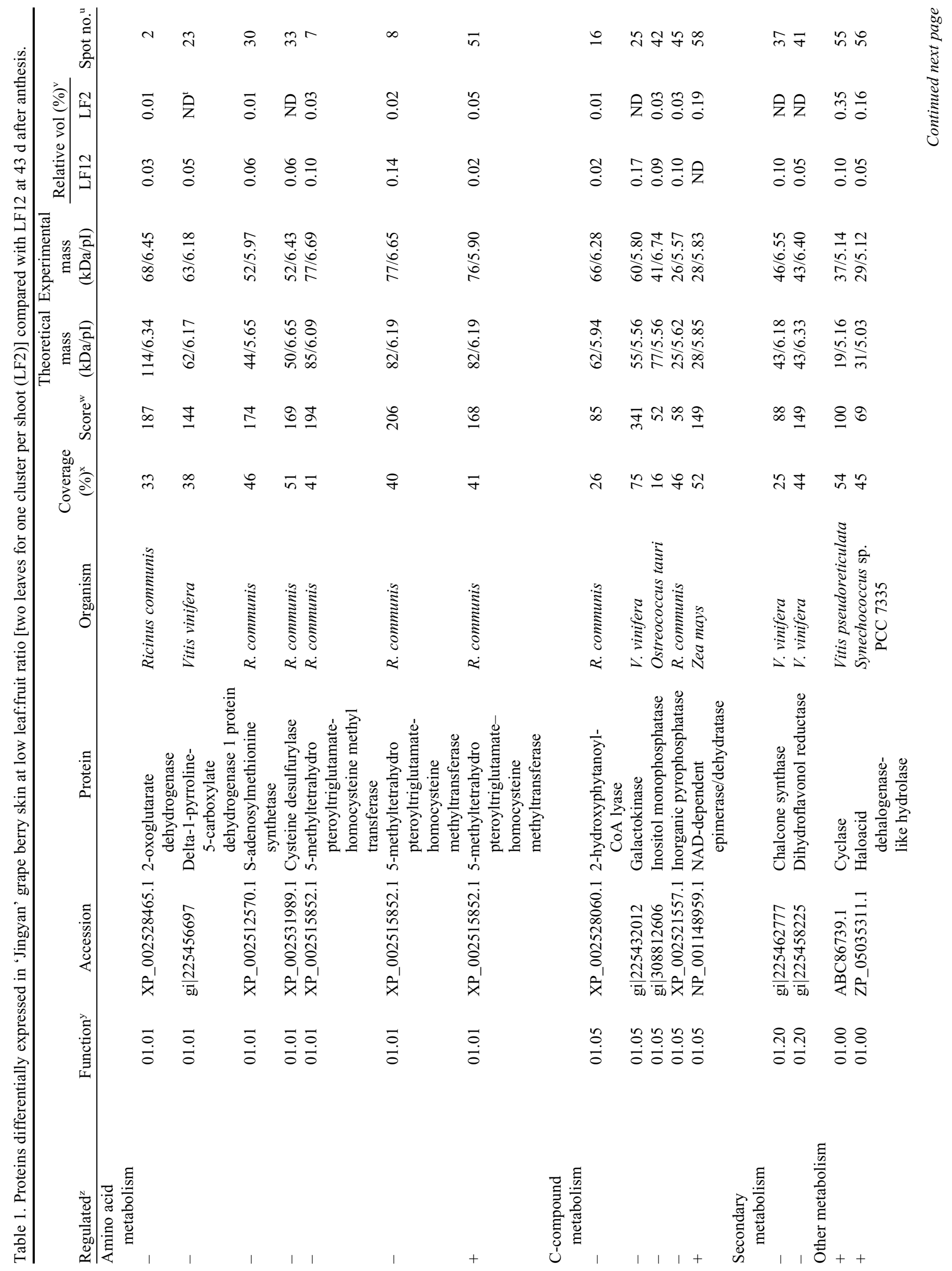




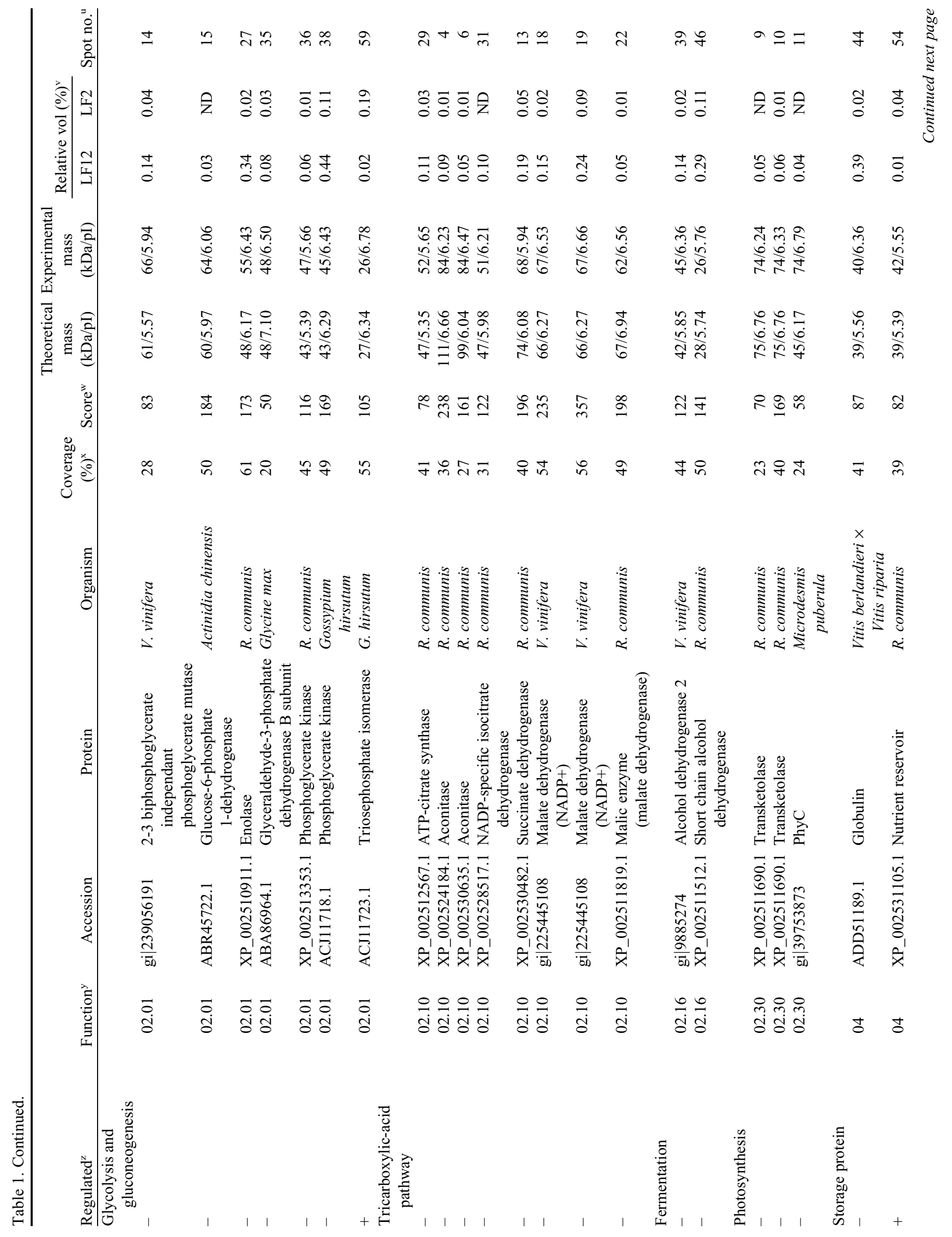




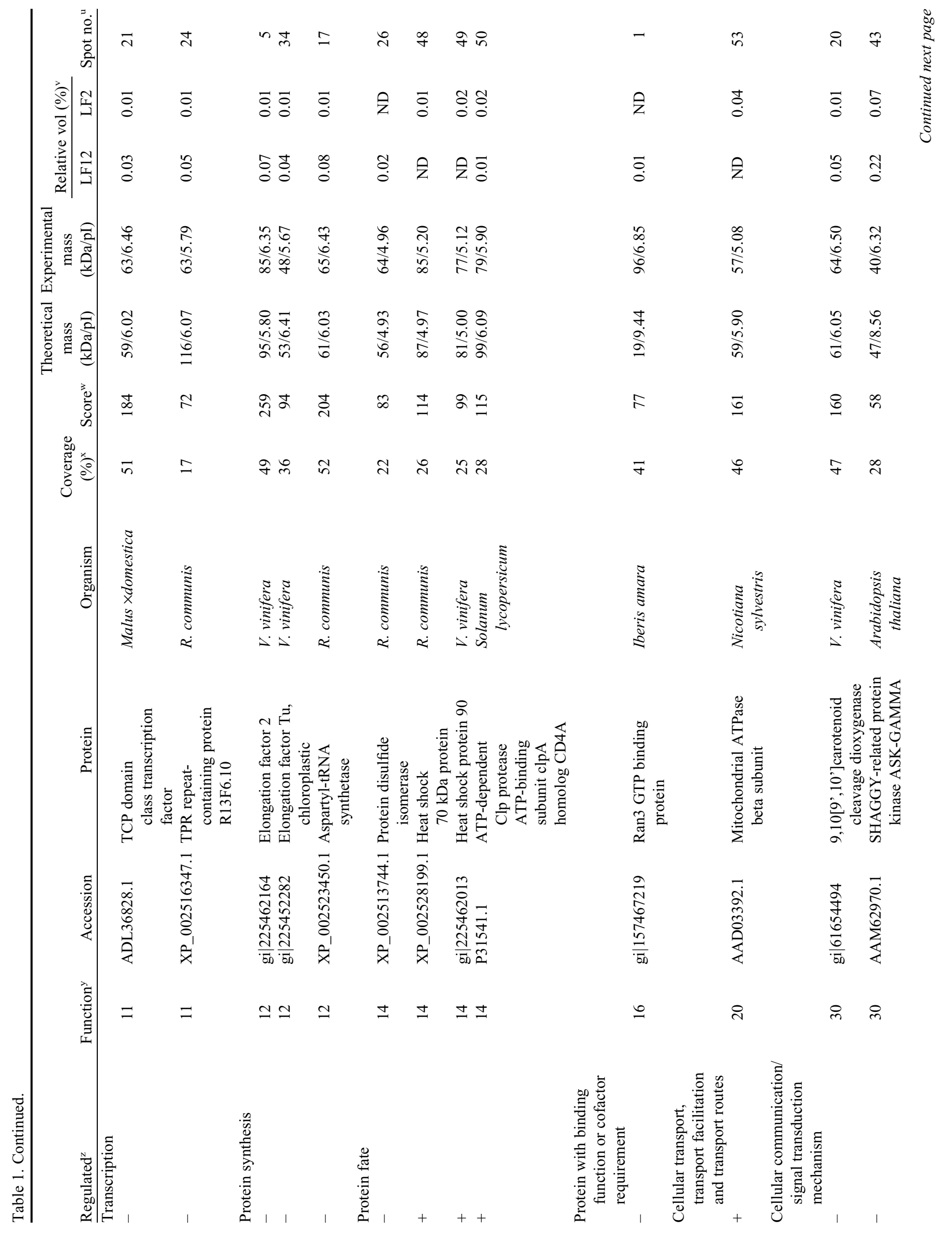




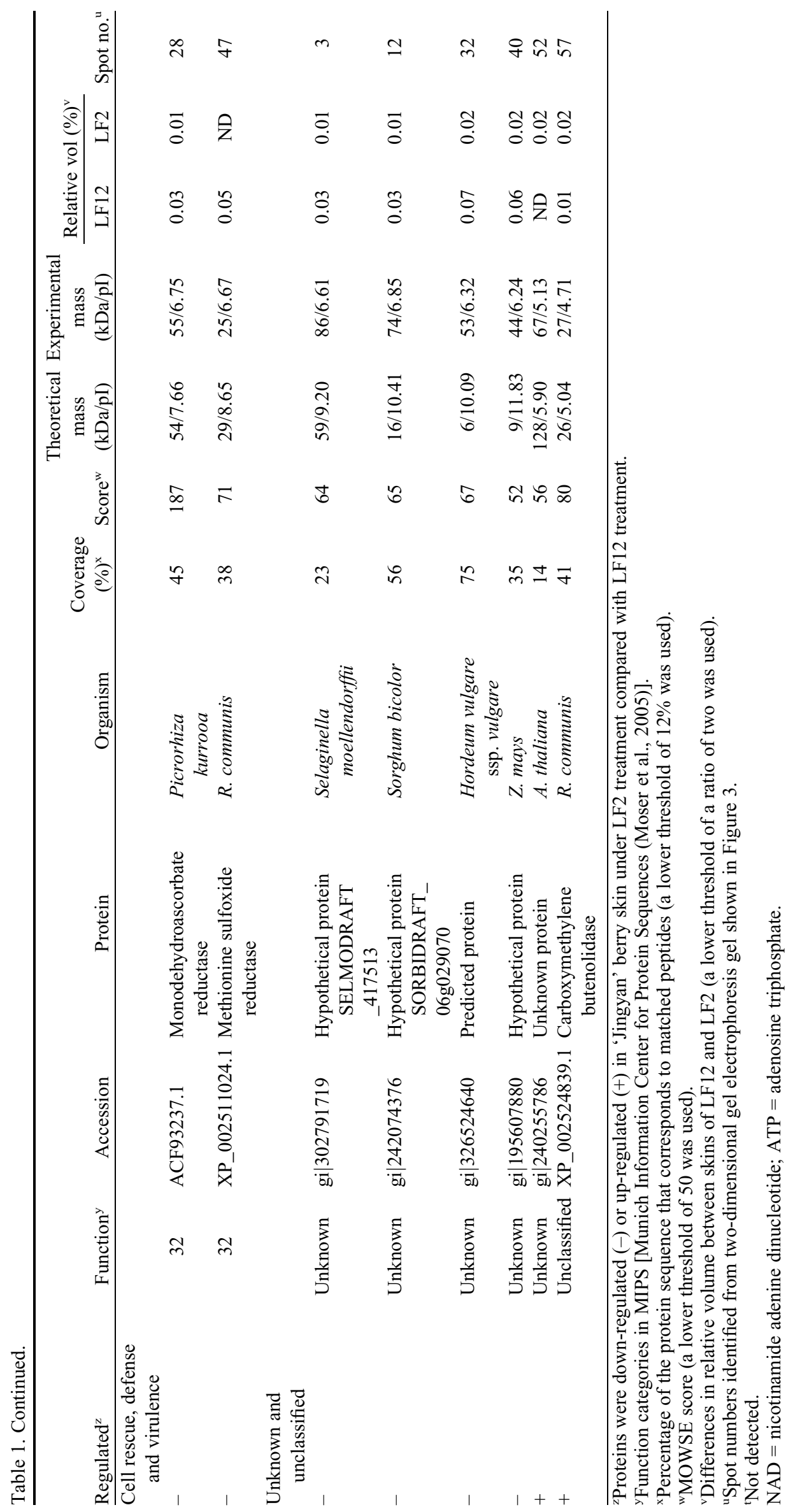


itself at the onset of coloring. In this study, the absence of assimilate supply at high cropload likely resulted in low C-compound metabolism and subsequently affected anthocyanin synthesis.

Proteins involved in Energy. The LF2 treatment resulted in down-regulation of the enzymes detected in the glycolysis, pentose phosphate, and gluconeogenesis pathways [function 02.01 (spots 14, 15, 27, 35, 36, 38)]. In the tricarboxylic acid cycle (function 02.10), five main enzymes were similarly down-regulated, including adenosine triphosphate (ATP)citrate synthase (spot 58), aconitase (spots 4, 6), and isocitrate dehydrogenase (spot 31) as the first three steps of the cycle; and succinate dehydrogenase (spot 13) and malate dehydrogenase (spots 18, 19, 22) as the last step. Malate and tartaric acid, a dihydroxyl derivative of succinate, are the main organic acids in grape berries (Liu et al., 2006). Understanding the effect of increased LF ratio on these proteins, especially malate dehydrogenase, may be the key to understanding the link between increased acidity and high cropload as was seen in this study. In the group of fermentation proteins identified (function 02.16), two isoforms of alcohol dehydrogenase (spots 39, 46), which catalyze a reaction as part of fermentation to ensure a constant supply of $\mathrm{NAD}^{+}$(Thompson et al., 2010), were down-regulated by high cropload. Although grouped in the photosynthesis category (function 02.30), transketolase (spots 9, 10) is an enzyme of both the Calvin cycle of photosynthesis and the pentose phosphate pathway. Negri et al. (2008b) found high expression of transketolase during grape berry ripening, which may be required in the skin for satisfying the large demand for carbon skeletons of the biosynthetic pathways operating in this tissue (e.g., anthocyanin synthesis). Phytochrome C (spot 11, function 02.30), a photoreceptor, has multiple functions throughout plant development. These may include working as a coactivator with phytochrome $\mathrm{A}$, which is able to activate elements of anthocyanin biosynthesis such as CHS (spot 37 this study) (Franklin et al., 2003; Møller et al., 2002). The low expression of transketolase and phytochrome $\mathrm{C}$ in berry skin at high cropload would not be conducive to anthocynin biosynthesis.

Almost all proteins involved in energy functions were downregulated in berry skin under LF2 treatment with only one protein, triosephosphate isomerase (spot 59), being found to be up-regulated. This protein plays an important role in glycolysis and is essential for efficient energy production. In addition, the mitochondrial ATPase beta subunit (spot 53), although classified into cellular transport in MIPS (function 20), can both move solutes across the membrane against their concentration gradient as well as catalyze the decomposition of ATP into adenosine diphosphate to release energy. The enhancement of these two proteins might compensate to a degree for the loss of energy caused by high cropload.

Proteins Involved in TRAnSCRIPTION. Transcription factors (function 11) play important roles in many biosynthetic processes, including anthocyanin biosynthesis in grape berry skin. $R 2 R 3 M Y B$, basic helix-loop-helix (bHLH, also known as $M Y C$ ), and $W D R$ families have been reported to be correlated with anthocyanin biosynthesis in grape berry skin (Broun, 2005). However, none of these families were differentially regulated in the berry skin concurrently with sizeable differences in anthocyanin content between LF12 and LF2 treatments, like in our previous study (Niu et al., 2013). It is possible that they were functionally accumulated at levels too low for our proteomic analyses to detect differences. However, two types of transcription factors were down-regulated in berry skin under LF2. The TCP domain class transcription factor family (spot 21) has been suggested to affect cell division, regulating plant growth and development (Cubas et al., 1999). Alternatively, TPR (spot 24) is a structural motif identified in a wide variety of proteins, mediating protein-protein interactions (Blatch and Lässle, 1999). Their down-regulation may indicate a general slowing of biosyntheses in berry skin under high cropload.

Proteins involved in Other Functions. Protein synthesis is likely to be reduced in berry skin under LF2 treatment, reflected by down-regulated elongation factors (spots 5, 34) and aspartyltRNA synthetase (spot 17) (Sauter et al., 2000). Protein disulfide-isomerase (spot 26), which was detected in the cell wall-enriched fraction of grape berry skin and is important for cell wall formation (Negri et al., 2008a), and Ran3 GTP binding protein (spot 16, function 16) were also down-regulated under LF2. However, heat shock proteins (spots 48, 49) and ATPdependent Clp protease ATP-binding subunit clpA homolog CD4A (spot 50), a member of the Hsp 100 family of heat shock proteins (Weber-Ban et al., 1999), were found to be upregulated. Heat shock proteins were generally found to accumulate when plants were exposed to elevated temperatures, abscisic acid, water stress, or other stresses (Hu et al., 2010). In this study, the up-regulation of heat shock proteins may be considered the response of the berry to unsuitable growth condition in the form of high cropload.

Four proteins (spots 20,43, 28, 47) connected to cellular signal transduction (function 30) and cell rescue and defense (function 32) were down-regulated under LF2. Carotenoid cleavage dioxygenase (spot 20) can catalyze a reaction yielding 3-hydroxy- $\beta$-ionone, a C13-norisoprenoidic compound. C13norisoprenoids are terpenoids found in many fruits, including grape berries, and contribute to aroma and flavor (Wirth et al., 2001). A significant induction of carotenoid cleavage dioxygenase expression approaching véraison until maturity has been observed in the grape berry (Mathieu et al., 2005). Its downregulation may result in loss of aroma and flavor in berries under LF2 treatment, although this needs further verification.

In addition, two storage proteins (function 04) were respectively down- and up-regulated in berry skin under LF2: globulin (spot 44), which often exists as storage protein within seeds, including grape (Zhou et al., 2010), and nutrient reservoir (spot 54). The relevance of these proteins to anthocyanin synthesis has not been documented.

\section{Conclusions}

A very high cropload (LF2) resulted in a lack of coloration and anthocyanin accumulation in berry skin, decreased berry weight and AAX, and increased TA compared with a high cropload (LF12). Comparative proteomics analysis provided a great deal of information, which may enhance our understanding of the effects of LF on berry skin, specifically in relation to anthocyanin biosynthesis. The anthocyanin biosynthesis pathway enzymes CHS and DFR were not detected in grape berry skin under low LF. Most other proteins involved in various functions including metabolism, energy, transcription, protein synthesis, binding, signal transduction, and cell defense were down-regulated, indicating that significant negative metabolic changes occurred. The failure to detect some enzymes and transcription factors involved in the anthocyanin biosynthetic pathway indicates a need for improved experimental 
conditions and further verification. Finally, it was a limitation of this study that the development of LF2 berries appeared to lag behind that of LF12 berries, which was reflected in berry growth and soluble sugars. Reducing cropload is often used in fruit crops, including grape (Carbonneau, 1997), as a means of quality control as well as a method of hastening fruit ripening. This method of reducing cropload has been applied to peach and resulted in 3 to $6 \mathrm{~d}$ slower development of fruit at high cropload compared with that at low cropload (Berman and DeJong, 1996). If fruit developmental stage had been a factor in the present experiment, one would have realized that some specific differences in proteomic profiles between LF treatments may relate to berry development.

\section{Literature Cited}

Artimo, P., M. Jonnalagedda, K. Arnold, D. Baratin, G. Csardi, E. de Castro, S. Duvaud, V. Flegel, A. Fortier, E. Gasteiger, A. Grosdidier, C. Hernandez, V. Ioannidis, D. Kuznetsov, R. Liechti, S. Moretti, K. Mostaguir, N. Redaschi, G. Rossier, I. Xenarios, and H. Stockinger. 2012. ExPASy: SIB bioinformatics resource portal. Nucleic Acids Res. 40:W597-W603.

Berman, M.E. and T.M. DeJong. 1996. Water stress and crop load effects on fruit fresh and dry weights in peach (Prunus persica). Tree Physiol. 16:859-864.

Blatch, G.L. and M. Lässle. 1999. The tetratricopeptide repeat: A structural motif mediating protein-protein interactions. Bioessays 21:932-939.

Boss, P.K., C. Davies, and S.P. Robinson. 1996. Analysis of the expression of anthocyanin pathway genes in developing Vitis vinifera $\mathrm{L}$. cv. Shiraz grape berries and the implications for pathway regulation. Plant Physiol. 111:1059-1066.

Bravdo, B., Y. Hepner, C. Loinger, S. Cohen, and H. Tabacman. 1985. Effect of irrigation and crop level on growth, yield and wine quality of Cabernet Sauvignon. Amer. J. Enol. Viticult. 36:132-139.

Broun, P. 2005. Transcriptional control of flavonoid biosynthesis: A complex network of conserved regulators involved in multiple aspects of differentiation in Arabidopsis. Curr. Opin. Plant Biol. 8:272-279.

Bunik, V.I. and A.R. Fernie. 2009. Metabolic control exerted by the 2-oxoglutarate dehydrogenase reaction: A cross-kingdom comparison of the crossroad between energy production and nitrogen assimilation. Biochem. J. 422:405-421.

Candolfi-Vasconcellos, M.C. and W. Koblet. 1990. Yield, fruit quality, bud fertility and starch reserves as a function of leaf removal in Vitis vinifera-Evidence of compensation and stress recovering. Vitis 29:199-221.

Carbonneau, A. 1997. General relationship within the whole-plant: Examples of the influence of vigour status, crop load and canopy exposure on the sink 'berry maturation' for the grapevine. Acta Hort. 427:99-118.

Castellarin, S.D., M.A. Matthews, G.D. Gaspero, and G.A. Gambetta. 2007. Water deficits accelerate ripening and induce changes in gene expression regulating flavonoid biosynthesis in grape berries. Planta 227:101-112.

Chacko, E.K., Y.T.N. Reddy, and T.V. Ananthanarayanan. 1982. Studies on the relationship between leaf number and area and development in mango (Mangifera indica L.). J. Hort. Sci. 57:483-492.

Chen, F., Z. Zhang, K. Lin, T. Qian, Y. Zhang, D. You, X. He, Z. Wang, J. Liang, Z. Deng, and G. Wu. 2012. Crystal structure of the cysteine desulfurase DndA from Streptomyces lividans which is involved in DNA phosphorothioation. PLoS ONE 7:e36635.

Cubas, P., N. Lauter, J. Doebley, and E. Coen. 1999. The TCP domain: A motif found in proteins regulating plant growth and development. Plant J. 18:215-222.

Deytieux, C., L. Geny, D. Lapaillerie, S. Claverol, M. Bonneu, and B. Donèche. 2007. Proteome analysis of grape skins during ripening. J. Expt. Bot. 58:1851-1862.
Dokoozlian, N.K. and D.J. Hirschfelt. 1995. The influence of cluster thinning at various stages of fruit development on Flame Seedless table grapes. Amer. J. Enol. Viticult. 46:429-436.

Edson, C.E., G.S. Howell, and J.A. Flore. 1995. Influence of crop load on photosynthesis and dry matter partitioning of Seyval grapevines. III. Seasonal changes in dry matter partitioning, vine morphology, yield, and fruit composition. Amer. J. Enol. Viticult. 46:478-485.

Etchebarne, F., H. Ojeda, and J.J. Hunter. 2010. Leaf:fruit ratio and vine water status effects on Grenache Noir (Vitis vinifera L.) berry composition: Water, sugar, organic acids and cations. South African J. Enol. Viticult. 31:106-115.

Franklin, K.A., S.J. Davis, W.M. Stoddart, R.D. Vierstra, and G.C. Whitelam. 2003. Mutant analyses define multiple roles for phytochrome C in Arabidopsis photomorphogenesis. Plant Cell 15:19811989.

Giribaldi, M., I. Perugini, F.X. Sauvage, and A. Schubert. 2007. Analysis of protein changes during grape berry ripening by 2-DE and MALDI-TOF. Proteomics 7:3154-3170.

Grimplet, J., M.D. Wheatley, H.B. Jouira, L.G. Deluc, G.R. Cramer, and J.C. Cushman. 2009. Proteomic and selected metabolite analysis of grape berry tissues under well-watered and water-deficit stress conditions. Proteomics 9:2503-2528.

Hesse, H., O. Kreft, S. Maimann, M. Zeh, and R. Hoefgen. 2004. Current understanding of the regulation of methionine biosynthesis in plants. J. Expt. Bot. 55:1799-1808.

Hilbert, G., J.P. Soyer, C. Molot, J. Giraudon, S. Milin, and J.P. Gaudilere. 2003. Effects of nitrogen supply on must quality and anthocyanin accumulation in berries of cv. Merlot. Vitis 42:69-76.

Holton, T.A. and E.C. Cornish. 1995. Genetics and biochemistry of anthocyanin biosynthesis. Plant Cell 7:1071-1083.

Howell, G.S., T.K. Mansfield, and J.A. Wolpert. 1987. Influence of training system, pruning severity, and thinning on yield, vine size, and fruit quality of Vidal blanc grapevines. Amer. J. Enol. Viticult. 38:105-112.

Hu, X., R. Liu, Y. Li, W. Wang, F. Tai, R. Xue, and C. Li. 2010. Heat shock protein 70 regulates the abscisic acid-induced antioxidant response of maize to combined drought and heat stress. Plant Growth Regulat. 60:225-235.

Hummell, A.K. and C.F. David. 1998. Interaction of crop level and fruit cluster exposure on 'Seyval Blanc' fruit composition. J. Amer. Soc. Hort. Sci. 123:755-761.

Hunter, J.J. and J.H. Visser. 1988. Distribution of ${ }^{14} \mathrm{C}$-photosynthetate in the shoot of Vitis vinifera L. cv. Cabernet Sauvignon II. The effect of partial defoliation. South African J. Enol. Viticult. 9:10-15.

Kliewer, W.M. and N.K. Dokoozlian. 2005. Leaf area/crop weight ratios of grapevines: Influence on fruit composition and wine quality. Amer. J. Enol. Viticult. 56:170-181.

Kliewer, W.M. and R. Weaver. 1971. Effect of crop level and leaf area on growth, composition and coloration of 'Tokay' grapes. Amer. J. Enol. Viticult. 22:172-177.

Kobayashi, S., N. Goto-Yamamoto, and H. Hirochika. 2004. Retrotransposon-induced mutations in grape skin color. Science 304:982.

Kobayashi, S., M. Ishimaru, C.K. Ding, H. Yakushiji, and N. Goto. 2001. Comparison of UDP-glucose: Flavonoid 3-O-glucosyltransferase (UFGT) gene sequences between white grapes (Vitis vinifera) and their sports with red skin. Plant Sci. 160:543-550.

Kobayashi, S.K., M. Ishimaru, K.H. Hiraoka, and C.H. Honda. 2002. $M y$ b-related genes of the Kyoho grape (Vitis labruscana) regulate anthocyanin biosynthesis. Planta 215:924-933.

Léchaudel, M., J. Joas, Y. Caro, M. Génard, and M. Jannoyer. 2005. Leaf:fruit ratio and irrigation supply affect seasonal changes in minerals, organic acids and sugars of mango fruit. J. Sci. Food Agr. 85:251-260.

Liang, Z.C., B.H. Wu, P.G. Fan, C.X. Yang, W. Duan, X.B. Zheng, C.Y. Liu, and S.H. Li. 2008. Anthocyanin composition and content in grape berry skin in Vitis germplasm. Food Chem. 111:837-844. 
Liu, H.F., B.H. Wu, P.G. Fan, S.H. Li, and L.S. Li. 2006. Sugar and acid concentrations in 98 grape cultivars analyzed by principal component analysis. J. Sci. Food Agr. 86:1526-1536.

Markham, G.D. and M.A. Pajares. 2009. Structure-function relationships in methionine adenosyltransferases. Cell. Mol. Life Sci. 66:636-648.

Martínez-Esteso, M.J., S. Sellés-Marchart, D. Lijavetzky, M.A. Pedreño, and R. Bru-Martínez. 2011. A DIGE-based quantitative proteomic analysis of grape berry flesh development and ripening reveals key events in sugar and organic acid metabolism. J. Expt. Bot. 62:2521-2569.

Mathieu, S., N. Terrier, J. Procureur, F. Bigey, and Z. Günata. 2005. A carotenoid cleavage dioxygenase from Vitis vinifera L.: Functional characterization and expression during grape berry development in relation to $\mathrm{C}^{13}$-norisoprenoid accumulation. J. Expt. Bot. 56:27212731.

Møller, S.G., P.J. Ingles, and G.C. Whitelam. 2002. The cell biology of phytochrome signaling. New Phytol. 154:553-590.

Morris, J.R., G.L. Main, and O.L. Oswald. 2004. Flower cluster and shoot thinning for crop control in French-American hybrid grapes. Amer. J. Enol. Viticult. 55:423-426.

Moser, C., C. Segala, P. Fontana, I. Salakhudtinov, P. Gatto, C. Moser, C. Segala, P. Fontana, I. Salakhudtinov, P. Gatto, M. Pindo, E. Zyprian, R. Toepfer, M.S. Grando, and R. Velasco. 2005. Comparative analysis of expressed sequence tags from different organs of Vitis vinifera $\mathrm{L}$. Funct. Integr. Genomics 5:208-217.

Negri, A.S., B. Prinsi, A. Scienza, S. Morgutti, M. Cocucci, and L. Espen. 2008a. Analysis of grape berry cell wall proteome: A comparative evaluation of extraction methods. J. Plant Physiol. 165:1379-1389.

Negri, A.S., B. Prinsi, M. Rossoni, O. Failla, A. Scienza, M. Cocucci, and L. Espen. 2008b. Proteome changes in the skin of the grape cultivar Barbera among different stages of ripening. BMC Genomics 9:378.

Niu, N., Y.G. Cao, W. Duan, B.H. Wu, and S.H. Li. 2013. Proteomic analysis of grape berry skin responding to sunlight exclusion. J. Plant Physiol. 170:748-757.

Petrie, P.R., M.C.T. Trought, and G.S. Howell. 2000. Fruit composition and ripening of Pinot Noir (Vitis vinifera L.) in relation to leaf area. Aust. J. Grape Wine Res. 6:46-51.

Reynolds, A.G. 1989. 'Riesling' grapes respond to cluster thinning and shoot density manipulation. J. Amer. Soc. Hort. Sci. 114:364-368.

Reynolds, A.G., R.M. Pool, and L.R. Mattick. 1986. Effect of shoot density and crop control on growth, yield, fruit composition and wine quality of 'Seyval blanc' grapevines. J. Amer. Soc. Hort. Sci. 111:55-63.
Robinson, S.P. and C. Davies. 2000. Molecular biology of grape berry ripening. Aust. J. Grape Wine Res. 6:175-188.

Saito, K., M. Kobayashi, Y. Tanaka, Z. Gong, and M. Yamazaki. 1999. Direct evidence for anthocyanidin synthase as a 2-oxoglutarate dependent dioxygenase: Molecular cloning and functional expression of a red form of Perilla frutescens. Plant J. 17:181-189.

Sauter, C., B. Lorber, J. Cavarelli, D. Moras, and R. Giegé. 2000. The free yeast aspartyl-tRNA synthetase differs from the tRNAAspcomplexed enzyme by structural changes in the catalytic site, hinge region, and anticodon-binding domain. J. Mol. Biol. 299:1313-1324.

Souty, M., M. Génard, M. Reich, and G. Albagnac. 1999. Effect of assimilate supply on peach fruit maturation and quality. Can. J. Plant Sci. 79:259-268.

Terrier, N., F.X. Sauvage, A. Ageorges, and C. Romieu. 2001. Changes in acidity and in proton transport at the tonoplast of grape berries during development. Planta 213:20-28.

Thompson, C., C. Fernandes, O. De Souza, L. De Freitas, and F. Salzano. 2010. Evaluation of the impact of functional diversification on Poaceae, Brassicaceae, Fabaceae, and Pinaceae alcohol dehydrogenase enzymes. J. Mol. Model. 16:919-928.

Weaver, R.J. 1963. Effect of leaf to fruit ratio on fruit quality and shoot development in 'Carignane' and 'Zinfandel' wine grapes. Amer. J. Enol. Viticult. 14:1-12.

Weber-Ban, E.U., B.G. Reid, A.D. Miranker, and A.L. Horwich. 1999. Global unfolding of a substrate protein by the Hsp100 chaperone ClpA. Nature 401:90-93.

Wirth, J., W. Guo, R.L. Baumes, and Z. Günata. 2001. Volatile compounds released by enzymatic hydrolysis of glycoconjugates of leaves and grape berries from Vitis vinifera Muscat of Alexandria and Shiraz cultivars. J. Agr. Food Chem. 49:2917-2923.

Wolpert, J.A., G.S. Howell, and T.K. Mansfield. 1983. Sampling Vidal blanc grapes. I. Effect of training system, pruning severity, shoot exposure, shoot origin, and cluster thinning on cluster weight and fruit quality. Amer. J. Enol. Viticult. 34:72-76.

Yamane, T. and K. Shibayama. 2006. Effects of trunk girdling and crop load levels on fruit quality and root elongation in 'Aki Queen' grapevines. J. Jpn. Soc. Hort. Sci. 75:439-444.

Yang, P.F., H. Chen, Y. Liang, and S.H. Shen. 2007. Proteomic analysis of de-etiolated rice seedlings upon exposure to light. Proteomics 7:2459-2468.

Yoon, S., W. Lee, M. Kim, T.D. Kim, and Y. Ryu. 2012. Structural and functional characterization of S-adenosylmethionine (SAM) synthetase from Pichia ciferrii. Bioprocess Biosyst. Eng. 35:173-181.

Zhou, T., Q. Li, J. Zhang, Y. Bai, and G. Zhao. 2010. Purification and characterization of a new 11S globulin-like protein from grape (Vitis vinifera L.) seeds. Eur. Food Res. Technol. 230:693-699. 